\title{
Prescrever "tempo verde": sobre outros modos de controle de sujeitos com Transtorno do Déficit de Atenção e Hiperatividade (TDAH) ${ }^{1}$
}

\author{
Prescribir "tiempo verde": sobre otros modos de control de los sujetos \\ con Trastorno del Déficit de Atención y Hiperactividad (TDAH) \\ Prescribe "green time": about other ways to control subjects \\ with Attention Deficit Hyperactivity Disorder (ADHD)
}

Thaís Presa Martins²

Rildo Goulart Peres ${ }^{3}$

Nádia Geisa Silveira de Souza ${ }^{4}$

\begin{abstract}
Resumo
O termo "natureza" designa uma construção cultural, que adquire diferentes significados ao longo do espaço/tempo, com determinados efeitos e fins. Neste sentido, o intuito do estudo foi analisar ditos tomados como verdade sobre a importância do contato com a "natureza", tendo como finalidade outros modos de controle de sujeitos com diagnóstico de TDAH. Para tanto, o embasamento pautou-se pelos Estudos Culturais pósestruturalistas. Os excertos do livro analisado têm a finalidade de educar os leitores, constituindo o entendimento sobre a falta de contato com a "natureza" articulada à criação do conceito de transtorno do déficit de natureza; a ideia de que o TDN seria uma noção mais abrangente do que o TDAH, e de que ambos poderiam ser tratados com a prescrição de "tempo verde"/terapia da "natureza".
\end{abstract}

Palavras-Chave: Contato com a Natureza; Disciplina; Estudos Culturais; Transtorno do Déficit de Natureza.

\section{Resumen}

El término "naturaleza" significa una construcción cultural que adquiere diferentes significados en el espacio/tiempo, con ciertos efectos y propósitos. En este sentido, el propósito del estudio fue analizar las declaraciones tomadas como verdaderas sobre la importancia del contacto con la "naturaleza", con el objetivo de otros modos de control de los sujetos diagnosticados con TDAH. Con este fin, la fundación fue guiada por los Estudios Culturales postestructuralistas. Los extractos del libro analizado están destinados a educar a los lectores, lo que constituye la comprensión de la falta de contacto con la "naturaleza" articulada con la creación del concepto de trastorno por déficit de la naturaleza; la idea de que el TDN sería una noción más amplia que el TDAH, y que ambos podrían tratarse con la prescripción de la terapia "tiempo verde"/"naturaleza".

\footnotetext{
${ }^{1}$ Este artigo corresponde a um recorte da Tese de Doutorado da primeira autora.

${ }^{2}$ Doutoranda pelo Programa de Pós-Graduação em Educação em Ciências da Universidade Federal do Rio Grande do Sul; Rio Grande do Sul, Brasil; contato: tpmmartins@gmail.com.

${ }^{3}$ Doutorando pelo Programa de Pós-Graduação em Educação em Ciências da Universidade Federal do Rio Grande do Sul; Rio Grande do Sul, Brasil.

${ }^{4}$ Profa. Dra. do Programa de Pós-Graduação em Educação em Ciências da Universidade Federal do Rio Grande do Sul; Rio Grande do Sul, Brasil.
} 
Palabras claves: Contacto con la Naturaleza; Disciplina; Estudios Culturales; Trastorno del Déficit de Naturaleza.

\begin{abstract}
The term "nature" designates a cultural construction, which acquires different meanings throughout space/time, with certain effects and purposes. In this sense, the objective of the study was to analyze truths about the importance of contact with "nature", aiming at other modes of control of subjects with ADHD diagnosis. For that, the foundation was based on Cultural Studies, poststructuralist. The excerpts of the book analyzed have the purpose of educating the readers, constituting the understanding about the lack of contact with the "nature" articulated to the creation of the concept of nature-deficit disorder; the idea that TDN would be a broader notion than ADHD, and that both could be treated with the prescription of "green time"/"nature" therapy.
\end{abstract}

Keywords: Contact with nature; Cultural Studies; Discipline; Nature-Deficit Disorder.

\title{
1. Introdução
}

Podemos pensar que o que denominamos "natureza" designa uma invenção histórica, social e cultural, criada numa rede de sentidos - saberes, noções, valores, imagens -, cujos discursos orientam os nossos modos de ser, estar, pensar, agir e consumir. A palavra "natureza" é uma complexa construção discursiva que se modificou e que se modifica conforme determinadas conjunturas sociais, históricas, espaciais e culturais nas e pelas quais é entendida. Refere-se a uma invenção, profundamente marcada por certos entendimentos morais, éticos e estéticos, que nos permitem estabelecer o que ver, o que admirar, o que conservar e o que proteger no mundo dito "natural". A "natureza" foi e é falada, narrada, pintada e apresentada nas e pelas culturas desde as pré-históricas artes rupestres e, sobretudo, na concepção atual do mundo, que "naturaliza" a "natureza", concebendo-a como algo que está dado como sinônimo de propriedades, bens e recursos "naturais" dos quais podemos usufruir; rompendo as suas inter-relações e ignorando a sua complexidade. Desde as primeiras tentativas do homem de observar e de conhecer a "natureza", podemos notar um afastamento do "cultural" em relação ao "natural", de maneira que a "natureza" foi sendo objetificada pela razão humana e sua "objetividade", promovendo uma "limpeza" e uma "purificação" do objeto, em uma ideia mecanicista de estudo da "natureza". Tal afastamento possibilitou que a "natureza" pudesse ser possuída e dominada pelo homem, influenciando fortemente a educação e o consumo contemporâneos (MARTINS, 2016).

Para pensarmos sobre a abrangência da palavra "natureza", além de dirigirmos os nossos olhares para o passado, precisamos analisar os fatores e os atores enredados na dinâmica contemporânea do mundo, ou seja, necessitamos observar as mudanças que estamos vivenciando. Hoje, vivemos em um mundo complexo, onde culturas, naturezas, tecnologias e relações de saber/poder articulam-se, transformando e produzindo nossas subjetividades, 
vindo a constituir nossos pensamentos, comportamentos, valores, desejos e corpos (MARTINS, 2016). Assim, consideramos importante atentar para os efeitos das tecituras culturais em que estamos inseridos, que nos ensinam o que é, o que valorizar, e a importância de estar em contato com a "natureza".

Neste sentido, o presente artigo aborda a "natureza" como uma construção cultural, que adquiriu/adquire diferentes significados e sentidos ao longo do tempo/espaço; em seguida, menciona a importância do contato com a "natureza" para a saúde e o bem-estar dos sujeitos, enfatizando a ideia da falta de contato com a "natureza" e possíveis problemas de saúde que a mesma poderia ocasionar - Transtorno do Déficit de Natureza e Transtorno do Déficit de Atenção e Hiperatividade. O intuito do estudo foi analisar ditos tomados como verdade sobre a importância do contato com a "natureza", tendo como finalidade outros modos de controle dos corpos de sujeitos com diagnóstico de Transtorno do Déficit de Atenção e Hiperatividade (TDAH). Para tanto, o embasamento teórico-metodológico pautouse pelo campo dos Estudos Culturais, em suas vertentes pós-estruturalistas, com inspiração na fase genealógica dos estudos foucaultianos.

\section{Notas sobre a importância do contato com a "natureza"}

Discursos sobre a importância do contato com a "natureza" para a saúde e o bem-estar dos sujeitos emergiram, no contexto Ocidental, durante a Antiguidade Grega (por volta de 400-300 a.C.), com a figura de Hipócrates de Cós, conhecido como o "Pai da Medicina". Ele postulou a existência de quatro fluidos (humores) principais do corpo: a bile amarela, a bile negra, o sangue e a fleuma ou a linfa. Esses humores resultavam da mistura dos quatro elementos da "natureza": água, ar, fogo e terra. Por exemplo, para a bile amarela o fogo era considerado o principal elemento, predominando a qualidade calor; na bile negra, a terra; na linfa, a água; e no sangue, ocorreria uma proporção aproximadamente igual entre os elementos (CAMARGO, 2008). A saúde, assim, seria o equilíbrio entre os humores. A obra hipocrática caracteriza-se pela valorização da observação empírica, considerando não só o paciente, mas o seu ambiente como um todo. No texto "Ares, Águas, Lugares", Hipócrates discute os fatores ambientais ligados às doenças, defendendo uma ideia ecológica de saúdeenfermidade. Daí, emerge a noção de que regiões insalubres podem propiciar a ocorrência de doenças - como a malária no sul da Europa, que contribuiu para a queda do Império Romano (SCLIAR, 2007). 
Com as mudanças no fazer científico ao longo dos tempos/espaços, no final do séc. XIX, ocorreu a chamada Revolução Pausteriana. Louis Pasteur revelou, por meio de seu microscópio, a existência de micro-organismos, que, a partir de então, puderam ser identificados e as suas respectivas doenças provocadas, prevenidas e curadas (SCLIAR, 2007). A Tuberculose é um exemplo interessante da importância do contato com a "natureza" para a saúde e o bem-estar dos sujeitos. Descoberta em 1882, é uma das doenças mais antigas que se conhecem. No século XIX, passou a ser tratada com a terapêutica higieno-dietética, consistindo em bons hábitos alimentares, repouso e o clima das montanhas (com ar "puro"). Para tanto, os pacientes eram isolados em sanatórios e preventórios (FIOCRUZ, 2013).

Conforme Scliar (2007), o conceito universal do que é saúde só pode ser concebido após a criação da Organização das Nações Unidas (ONU) e da Organização Mundial de Saúde (OMS). Divulgado em 7 de abril de 1948 e estando implicado o reconhecimento do direito à saúde como obrigação do Estado, estabeleceu-se que: "Saúde é o estado do mais completo bem-estar físico, mental e social e não apenas a ausência de enfermidade" (idem, p. 37). Devido à amplitude do conceito, o mesmo sofreu críticas, sendo substituído, em 1977, por: "Saúde é a ausência de doença" (idem, p. 37). Por conta de inúmeras discussões, a Constituição Federal Brasileira de 1988, artigo 196, diz que: "A saúde é direito de todos e dever do Estado, garantido mediante políticas sociais e econômicas que visem à redução do risco de doença e de outros agravos e ao acesso universal e igualitário às ações e serviços para a promoção, proteção e recuperação" (idem, p. 39) - princípio este que norteia o Sistema Único de Saúde (SUS).

Nas últimas décadas, o ritmo frenético do processo de urbanização e do aumento do uso das tecnologias têm trazido consequências para a constituição dos sujeitos, promovendo efeitos negativos para o bem-estar e para a saúde física e mental das pessoas. O contato, sobretudo, das crianças e dos jovens com a "natureza" (referindo-se, aqui, a parques, praças, áreas verdes do meio urbano e rural) vêm diminuindo; acarretando, por exemplo, aumento dos índices de obesidade, do déficit de vitamina $\mathrm{D}$ e dos casos diagnosticados de Transtorno do Déficit de Atenção e Hiperatividade (TDAH) - discutido a seguir. Tal desconexão com a "natureza" e seus efeitos para os seres humanos deram origem ao Transtorno do Déficit de Natureza (LOUV, 2016).

O termo Transtorno do Déficit de Natureza (TDN) foi cunhado pelo autor e jornalista norte-americano Richard Louv, em 2005, nos Estados Unidos, em seu livro best-seller "Last 
Child in the Woods: saving our children from nature-deficit desorder"; traduzido para o português como "A Última Criança na Natureza: resgatando nossas crianças do transtorno do déficit de natureza". A obra é a primeira a reunir um novo e crescente corpo de pesquisas, indicando que a exposição direta à "natureza" é essencial para o desenvolvimento saudável e para a saúde física e emocional de crianças e adultos. Mais do que apontar e discutir tais questões, Louv indica soluções para "curar o vínculo quebrado": a) 100 ações que você pode tomar para criar mudanças em sua comunidade, escola e família; b) 35 pontos de discussão para inspirar pessoas de todas as idades a falar sobre a importância da natureza em suas vidas; c) um novo relatório de progresso do autor sobre o crescente movimento "Leave No Child Inside" ("Não Deixe Nenhuma Criança Dentro") (LOUV, 2016; 2018). Neste artigo, fizemos um breve recorte analítico da noção de TDN, apresentado posteriormente.

Este assunto, curiosamente, começou a ser abordado pelos meios de comunicação de massa do Brasil apenas durante o ano de 2016. O programa Bem-Estar da Rede Globo de Televisão foi um dos primeiros meios a tratar do tema, lançando mão de discursos biomédicos e de um vídeo documentário do Instituto Alana para explicar sobre a importância do contato com a "natureza" para, por exemplo: desenvolver os sentidos, melhorar a concentração e a memória, aumentar os níveis de inteligência, o equilíbrio e o rendimento escolar/acadêmico, ter sensação de felicidade e de bem-estar (BEM-ESTAR, 2016; ÉPOCA, 2016a; 2016b).

\subsection{Sob as lentes dos Estudos Culturais}

Nesta perspectiva, o embasamento teórico-metodológico da pesquisa pautou-se pelo campo dos Estudos Culturais, em suas vertentes pós-estruturalistas, com inspiração na fase genealógica dos estudos foucaultianos. De acordo com Wortmann et al. (2007), os Estudos Culturais - em articulações com a educação, a ciência, a mídia, o corpo, a "natureza" questionam as novas configurações da cultura, os novos mapas culturais e as novas configurações sociais; bem como os saberes estabelecidos e legitimados pela tradição, pela erudição e pelas investigações científicas. Além disso, este campo dedica-se a analisar a multiplicidade das produções culturais que nos subjetivam, de modo a abandonar os enfoques escolares geralmente utilizados no campo educativo (pela Educação em Ciências e pela Educação Ambiental, aqui, especialmente), discutindo e tensionando os discursos e as práticas circulantes nas escolas, nas instituições de modo geral, e nos processos culturais.

Assim, analisamos como e de que lugar se fala sobre a importância do contato com a "natureza" tendo como finalidade o controle dos corpos de sujeitos com diagnóstico de 
Transtorno do Déficit de Atenção e Hiperatividade (TDAH). Os ditos analisados consistem em excertos extraídos da obra de referência em que a noção de Transtorno do Déficit de Natureza (TDN) foi cunhada pela primeira vez - o livro "A Última Criança na Natureza: resgatando nossas crianças do transtorno do déficit de natureza”. Neste artigo, atentamos especificamente para excertos extraídos do capítulo 8 da obra referida - "Transtorno do déficit de natureza e o ambiente restaurador", no qual o autor comenta sobre a importância do contato com a "natureza" como "um novo campo de terapia para síndromes como o transtorno do déficit de atenção" (LOUV, 2016, p. 75).

\subsection{O Transtorno do Déficit de Atenção e Hiperatividade (TDAH)}

Como dito anteriormente, o Transtorno do Déficit de Atenção e Hiperatividade vem sendo associado à falta de contato com a "natureza", ou seja, se tivéssemos mais proximidade com parques, praças e áreas verdes de modo geral seríamos seres humanos mais focados, atentos e tranquilos. Para podermos analisar esta relação na seção seguinte, apresentamos, agora, uma breve contextualização sobre os sintomas, o diagnóstico, a prevalência, e a operação da (in) disciplina concernente ao TDAH em âmbito escolar.

Segundo a quinta edição do Manual Diagnóstico e Estatístico de Transtornos Mentais (DMS-V), elaborado pela American Psychiatric Association (APA, 2013), a etiologia do TDAH é multifatorial, uma vez que se trata de um transtorno neurobiológico, desencadeado por condições genéticas e ambientais, que acomete o funcionamento de neurotransmissores na região frontal do córtex predominantemente. Essa estrutura é responsável pela inibição do comportamento, impedindo condutas consideradas socialmente inadequadas. No TDAH, a capacidade de prestar atenção, a memória, o autocontrole, a organização e o planejamento ficam comprometidos.

O TDAH é o problema psiquiátrico mais comumente diagnosticado em crianças, com uma prevalência de 3 a $6 \%$ da população mundial, podendo acompanhar o indivíduo por toda a vida. Os sintomas do transtorno apresentam-se em três diferentes tipos, incluindo: desatenção, hiperatividade, impulsividade, ou a forma combinada. Quando o jovem tem sintomas predominantes do tipo desatento, há maiores prejuízos de aprendizagem. No quadro predominantemente hiperativo-impulsivo, o indivíduo traz mais prejuízos nas interações sociais. Na apresentação combinada, o prejuízo incide tanto na aprendizagem quanto nas interações sociais (APA, 2013). No entanto, alguns autores vêm posicionando-se de forma crítica em relação ao que consta como referência diagnóstica no DSM-V, dentre eles, Colares; Moysés (1994, p. 29), pois "trata-se de uma pretensa doença neurológica jamais comprovada; 
inexistem critérios diagnósticos claros e precisos como exige a própria ciência neurológica; o conceito é vago demais, abrangente demais...".

A medicalização de crianças e de jovens brasileiros a partir do diagnóstico de Transtorno do Déficit de Atenção e Hiperatividade, com base em seus desempenhos escolares, tornou-se um importante tema nas discussões sobre Educação na última década. A associação entre problemas neurológicos, dificuldade de aprendizado e indisciplina apresentase como um discurso cada vez mais frequente no cotidiano escolar, tendo como consequência o crescimento do número de alunos encaminhados aos serviços de saúde. Neste sentido, a medicalização do "não aprender" tornou-se uma ideia corrente e uma poderosa estratégia disciplinar dos corpos dos sujeitos.

Conforme Foucault (1999), o momento histórico das disciplinas é o momento em que nasce uma arte do corpo humano, que objetiva não unicamente ao aumento de suas habilidades, nem tampouco ao aprofundamento de sua sujeição, mas sim a formação de uma relação que no mesmo mecanismo o torna tanto mais obediente quanto é mais útil, e inversamente. Forma-se, então, uma política das coerções que são um trabalho sobre o corpo, uma manipulação calculada de seus elementos, de seus gestos, de seus comportamentos. O corpo humano entra em uma maquinaria de poder que o esquadrinha, o desarticula e o recompõe. Uma "anatomia política", que é igualmente uma "mecânica do poder"; ela define como se pode ter domínio sobre o corpo dos outros, não simplesmente para que façam o que se quer, mas para que operem como se quer, com as técnicas, a rapidez e a eficácia que se determinam.

A disciplina fabrica sujeitos, ela é a técnica específica de um poder que toma os indivíduos tanto como objetos quanto como instrumentos de seu exercício; visto que "o poder não é a disciplina; a disciplina é um procedimento possível de poder" (FOUCAULT, 1994, p. 590). Segundo Elias (1989), o poder disciplinar", para Foucault, "não opõe simplesmente as necessidades e os desejos individuais, mas deve seu sucesso precisamente à sua habilidade em liberar a energia psíquica e libidinal no próprio processo de ligá-la aos objetivos produtivos de uma economia capitalista racionalista” (idem, p. 356). Assim, o poder disciplinar dispõe de instrumentos simples, como a "sanção normalizadora" - que traça limites entre

\footnotetext{
${ }^{5}$ De acordo com Foucault (1988) apud Veiga-Neto (1996), a afirmativa "pensar disciplinarmente contribui para que cada indivíduo se transforme num sujeito" apresenta duplo sentido, pois cada um passa a ser um sujeito e, também, cada um se sujeita a (se torna "sujeitável a", "capturável por" ou "alcançável por") um novo poder moderno - justamente o poder disciplinar.
} 
normal/anormal ${ }^{6}$ e aceitável/inaceitável, e cria um sistema de micropenalidades para barrar e punir qualquer desvio: desobediência, atraso, desatenção, grosseria, etc.; em suma, o que foge à norma disciplinar (FOUCAULT, 1999). Tal poder disciplinar e docilizante é encontrado tanto nos discursos e práticas escolares quanto médicos. Neste sentido, podemos entender em que condições emerge o discurso do desempenho escolar inaceitável atrelado à necessidade de medicalização daqueles que apresentam comportamentos desviantes da norma.

Ao ser individualizada, a criança passa a ser um objeto de análise descritiva passível de administração, submissão e controle, enfim, um corpo dócil. A invenção da infância implica na produção de saberes e de verdades com a finalidade de descrever a criança, classificá-la, compará-la, diferenciá-la, hierarquizá-la, excluí-la, homogeneizá-la; de acordo com novas regras ou com normas disciplinares. Impõe-se sobre a infância uma ordem normativa que lhe dá uma certa visibilidade, uma vez que o exercício da disciplina supõe um dispositivo que obriga ao jogo do olhar (FOUCAULT, 1999).

A medicina define tanto o "normal" quanto o "anormal", devido à potência de seu discurso científico, que circula pelo campo social em posição semelhante a uma "verdade dogmática". O discurso médico insere-se nos cálculos e nas técnicas de governo, tornando-se o saber legitimado em todas as esferas sociais, atuando sobre o corpo e, também, sobre as leis, as normas, os costumes, entremeando-se com a cultura (FOUCAULT, 2014). Collares; Moysés (1989) concebem que medicalizar uma questão é buscar as causas e as soluções médicas para questões não médicas. Este processo ocorre em uma perspectiva restrita, associal, ahistórica e acrítica da medicina, e não segundo uma corrente médica que encara as questões de saúde como determinadas pela forma de inserção do sujeito em uma determinada conjuntura social, histórica, cultural. Buscam-se causas médicas, no sentido puramente orgânico e centrado no indivíduo, por mecanismos fisiopatológicos extremamente sofisticados e, por vezes, "não comprovados".

\section{Prescrever "tempo verde" para o tratamento de TDAH?}

As seções devem ser numeradas com números arábicos a partir do 1 (um) e ter o título alinhado à esquerda. Já as subseções devem seguir a numeração progressiva a partir da seção

\footnotetext{
${ }^{6}$ Ewald (1993) apud Veiga-Neto (1996) afirma que, no início do século XIX, ocorreu uma alteração de sentidos entre as palavras regra e norma. Norma passa a referir-se a uma maneira de produzir as regras e de valorá-las. Isso leva ao conceito de normal e gera o seu oposto: o anormal, o patológico. Assim, num sentido moderno, a norma constitui-se em princípio de avaliação, fornecendo-nos padrões comparativos.
} 
primária e também devem estar alinhadas à esquerda e em negrito. Nesta seção, apresentamos e analisamos dois excertos extraídos da obra de referência mencionada anteriormente, considerando os chamados transtornos do déficit de natureza (TDN) e de atenção e hiperatividade (TDAH) como construções culturais, resultantes da ideia da falta de contato com a "natureza" - que, por sua vez, também designa uma invenção...

Excerto 1 - [...] Estudos sugerem que a natureza pode ser útil como ferramenta terapêutica para o TDAH (transtorno do déficit de atenção e hiperatividade), em paralelo com ou, quando apropriado, até substituindo medicamentos ou terapias comportamentais. Alguns pesquisadores hoje recomendam que pais e educadores propiciem mais experiências na natureza - em especial lugares onde haja verde para crianças com TDAH, oferecendo, assim, suporte para a função de atenção e minimizando os sintomas. Aliás, essa pesquisa inspira o uso do termo mais amplo "transtorno do déficit de natureza" como forma de entender melhor o que muitas crianças passam, quer tenham sido diagnosticadas com TDAH, ou não. De novo, o termo transtorno do déficit de natureza não está sendo usado com sentido científico ou clínico. Com certeza nenhum pesquisador acadêmico faz uso desse termo, ainda, nem atribui o TDAH totalmente ao déficit de natureza. No entanto, tendo como base cada vez mais evidências científicas, acredito que o conceito - ou a hipótese - do transtorno do déficit de natureza seja adequado e útil como descrição leiga a um fator que pode agravar as dificuldades de atenção de muitas crianças (LOUV, 2016, p. 120, grifos dos autores).

A partir do excerto 1, podemos observar que Richard Louv faz uma diferenciação entre TDN e TDAH - “o uso do termo mais amplo 'transtorno do déficit de natureza' como forma de entender melhor o que muitas crianças passam, quer tenham sido diagnosticadas com TDAH, ou não" - concebendo o transtorno do déficit de natureza como um conceito mais abrangente do que o transtorno do déficit de atenção e hiperatividade. Seguindo este raciocínio, quem sofre de TDN não necessariamente apresentaria TDAH, mas quem porta TDAH teria TDN, visto que problemas de atenção, hiperatividade e/ou impulsividade estariam diretamente relacionados à falta de contato com a "natureza". Além disso, ao afirmar que estudos sugerem que a "[...] natureza pode ser útil como ferramenta terapêutica para o TDAH (transtorno do déficit de atenção e hiperatividade), em paralelo com ou, quando apropriado, até substituindo medicamentos ou terapias comportamentais" - o autor menciona que áreas verdes configuram-se como um tipo de terapia - e, talvez, um dos melhores - para o tratamento de TDAH, uma vez que oferece "suporte para a função de atenção minimizando os sintomas ${ }^{7, .}$.

\footnotetext{
${ }^{7}$ Tais considerações vão ao encontro da visão biocêntrica/romântica de "natureza", enfatizada na análise do excerto 2 .
} 
Outro trecho interessante mostrado pelo excerto 1 é: "[...] o termo transtorno do déficit de natureza não está sendo usado com sentido científico ou clínico. Com certeza nenhum pesquisador acadêmico faz uso desse termo, ainda, nem atribui o TDAH totalmente ao déficit de natureza. No entanto, tendo como base cada vez mais evidências científicas, acredito que o conceito - ou a hipótese - do transtorno do déficit de natureza seja adequado e útil como descrição leiga a um fator que pode agravar as dificuldades de atenção de muitas crianças". Tal afirmação é conflitante, pois ao mesmo tempo em que Louv enfatiza que o TDN não deve ser encarado como um termo científico ou clínico lança mão de "evidências científicas": pesquisas, pesquisadores e dados científicos como estratégias para atribuir "veracidade" ao transtorno.

Para Latour; Woolgar (1997) e Latour (2001), a ciência - seus cientistas, suas práticas, seus instrumentos, seus interesses, seus recursos e suas regras - constrói uma determinada "realidade", aceita por esta rede tecnocientífica para que ocorra o processo de produção das "verdades" e dos "enunciados" ditos científicos. Assim, compreendemos que a ciência colocase em um lugar afastado da "natureza", a fim de poder conhecê-la, dominá-la e explorá-la; constituindo os seus "fatos científicos", que a "representarão como ela é", ou seja, que "descobrirão" e "revelarão" o que é a "natureza", o que está nela e como poderemos utilizar a mesma em nosso próprio benefício. Souza (2001) considera o conhecimento científico como uma prática cultural que (re) significa o "real", sendo um produtor de "verdades" histórica e socialmente contingentes. Logo, podemos afirmar que a ciência legitima as suas ações e o seu discurso científico por meio de um regime de normalizações, no qual relações de saber/poder presentes constituem quais saberes serão válidos ou "verdadeiros" - seus "regimes de verdade".

Neste sentido, o processo de diagnóstico e de medicalização do TDAH em crianças e jovens parece tornar-se cada vez mais sofisticado, na medida em que o discurso médico adquire mais técnicas e argumentos científicos que lhe conferem credibilidade e legitimidade social. Transpondo a concepção de medicalização para o âmbito escolar, pode-se afirmar que ela objetiva o corpo do sujeito, constituindo-o e subjetivando-o. Ao apontar o aluno considerado "desviante" tanto por seu desempenho escolar e/ou indisciplina quanto pelo discurso médico que o diagnostica clinicamente como portador de TDAH, ocorre um processo de estigmatização do indivíduo, que é posto na posição de "anormal". Assim, pensamos que o diagnóstico de TDAH funciona como uma estratégia disciplinar, a fim de garantir a existência de uma massa homogênea e "dócil" de alunos e de futuros profissionais, que sejam "úteis" para obedecer e cumprir determinadas normas e tarefas sociais. Como 
consequência deste diagnóstico escolar e médico, seguido por um processo de medicalização (conjunto com um incentivo ao contato com a "natureza" ou não) - muitas vezes, feito sem considerar aspectos sociais, culturais e familiares dos indivíduos -, há uma repressão, por exemplo, dos comportamentos questionadores das crianças e dos jovens.

Excerto 2 - [...] E, como Kuo destaca, prescrever "tempo verde" para o tratamento de TDAH tem outras vantagens: é amplamente acessível, livre de efeitos colaterais, não estigmatizado e barato. Se é fato que a terapia na natureza reduz os sintomas de TDAH, então o oposto também pode ser verdade: o TDAH pode ser um conjunto de sintomas mas agravado pela ausência de exposição à natureza. Seguindo essa linha de raciocínio, muitas crianças podem se beneficiar com medicamentos, mas o verdadeiro distúrbio está menos na criança do que no ambiente imposto e artificial. Visto por esse ângulo, a sociedade que desconectou as crianças da natureza com quase toda certeza está desajustada, ainda que bem-intencionada. Tirar a natureza e o brincar nela das crianças pode ser equivalente a tirar seu oxigênio (LOUV, 2016, p. 129, grifos dos autores).

No excerto 2, inicialmente, Louv traz a prescrição "tempo verde para o tratamento de $T D A H$ " como uma alternativa a medicamentos, visto que é "amplamente acessivel, livre de efeitos colaterais, não estigmatizado e barato” em relação aos mesmos. Em seguida, há uma nítida associação entre a ideia de terapia na "natureza"/aumento da exposição à "natureza" às visões biocêntricas/românticas do meio "natural" - "a sociedade que desconectou as crianças da natureza com quase toda certeza está desajustada, ainda que bem-intencionada”.

Segundo Carvalho (2010), a noção restauradora de "natureza" como sinônimo de algo puro e íntegro pode começar a ser construída no contexto social, econômico e ambiental da emergência das novas sensibilidades, durante o período da Revolução Industrial, e, posteriormente, aprofundada pelo advento do Romantismo. Tais sensibilidades idealizavam a "natureza" enquanto uma reserva do bem, da beleza e da "verdade", um ideal estético, ético e moral. Junqueira; Kindel (2009), por sua vez, dizem que apresentamos, simultaneamente, uma visão de busca por um retorno à "natureza" e uma visão cartesiana de "natureza". $\mathrm{Na}$ primeira noção, a "natureza" é vista como um "paraíso perdido" ao qual precisamos regressar, ao identificarmos nesta "natureza" as características primitivas, originais e "verdadeiras" da "essência" animal e animal-humana. Na segunda noção, esta "natureza" que deve ser buscada é tida como uma fonte de bens e de recursos "naturais" que podem ser explorados conforme as necessidades humanas; evidenciando a visão antropocêntrico-utilitarista que temos sobre a "natureza". Para as autoras, a "natureza" seria "[...] vista como espaço de inocência, como um lugar não corrompido, que segue leis próprias, que é regido pelas forças do universo" (idem, 
p. 151). Designando, então, a procura por uma "natureza" intocada e idealizada, um retorno ao lugar onde a vida é pura e afastada do caos urbano.

Nesta direção, Richard Louv parece estar alinhado a enunciados acerca de uma visão de retorno à "natureza" como sinônimo de origem, essência, lugar equilibrado, sagrado, que está distante do caos urbano, dos inúmeros estímulos visuais, sonoros e sinestésicos que nos interpelam cotidianamente, das diversas atribuições e pressões a que somos submetidos nos ambientes de estudo/trabalho. Em outras palavras, Louv alude à importância do ser humano procurar "(re)conectar-se" consigo mesmo e com os demais seres vivos. Assim, o excerto 2 ensina-nos a sermos parte integrante desta "natureza" equilibrada, íntegra e restauradora, a estarmos na "natureza" cuidando da mesma e conservando-a - ao mesmo tempo em que ela cuida de nós, trazendo benefícios para a nossa saúde e para o nosso bem-estar.

\section{Considerações Finais}

O livro "A Última Criança na Natureza" ensina-nos certos modos de sentir, de pensar, de estar e de agir em relação à "natureza", articulando determinados enunciados produtores de sentido. Os excertos analisados têm a finalidade de educar os sujeitos leitores, construindo o entendimento sobre a falta de contato com a "natureza" articulada à criação do conceito de transtorno do déficit de natureza. Assim, o TDN constituiria uma noção mais abrangente do que o TDAH, e ambos os transtornos poderiam ser tratados com a prescrição de "tempo verde" / de terapia da "natureza". Neste sentido, Richard Louv comercializa uma visão de "natureza" como sinônimo de "essência" e de "(re)conexão" consigo e com o planeta; uma "natureza" estética, ética e moralmente benéfica, que deve ser buscada, preservada e cuidada, a partir dos ensinamentos da sua obra.

Em suma, consideramos ser de extrema importância analisar os significados e os sentidos sobre a "natureza" postos em circulação no nosso cotidiano, interpelando-nos, subjetivando-nos e educando-nos. Tal exercício pode criar condições para, talvez, pensarmos de outro modo sobre as relações que temos desenvolvido com a "natureza" e sobre os transtornos psicossomáticos associados à falta de contato com a mesma.

Por fim, deixamos algumas questões em aberto acerca do que está sendo posto em jogo na área da Educação: O que é considerado "indisciplina" escolar e em que condições este processo de exclusão ocorre? Que tipo de escola e de sociedade "normal" e "disciplinada" estamos formando? Será que a escola tem funcionado como um espaço para mudanças de posturas e de ações, ou propiciado a repetição de determinados tipos de conduta? Que tipo de 
alunos, de futuros profissionais, e de cidadãos queremos constituir para agir no complexo, imagético e frenético mundo atual?

\section{Referências}

AMERICAN PSYCHIATRIC ASSOCIATION (APA). Manual de Diagnóstico e Estatística dos Transtornos Mentais (DSM-V), 5ed, 2013.

BEM-ESTAR. Bem Estar explica a importância de conectar saúde e natureza. Rede Globo de Televisão. [Programa televisivo]. Disponível em:

<http://g1.globo.com/bemestar/noticia/2016/06/bem-estar-investiga-relacao-entre-nossasaude-e-natureza.html >. Acesso em: 01 de ago. de 2018.

CAMARGO, Tatiana Souza de. Você é o que você come? Os cuidados com a alimentação: implicações na constituição dos corpos. Dissertação (Mestrado) - Programa de PósGraduação em Educação em Ciências: Química da Vida e Saúde, Universidade Federal do Rio Grande do Sul, Porto Alegre, 2008. Disponível em: 〈http://hdl.handle.net/10183/13087>. Acesso em: 18 de ago. de 2018.

CARVALHO, Isabel Cristina de Moura. Os Sentidos de "Ambiental”: a contribuição da hermenêutica à pedagogia da complexidade. In: LEFF, H. (Org.). A Complexidade Ambiental. São Paulo: Cortez, 2010.

COLLARES, Cecília Azevedo Lima; MOYSÉS, Maria Aparecida Affonso. Educação, Saúde e Formação da Cidadania na Escola. Educação e Sociedade. São Paulo, v.10, n.32, pp.73-87, 1989.

A Transformação do Espaço Pedagógico em Espaço Clínico - (A Patologização da Educação). Série Idéias, n.23. São Paulo: FDE, 1994, pp.25-31.

ÉPOCA. Estamos sofrendo o transtorno de déficit de natureza. Blog do Planeta. 31 de out. de 2016(a). [Internet]. Disponível em: 〈http://epoca.globo.com/colunas-e-blogs/blog-doplaneta/noticia/2016/06/estamos-sofrendo-o-transtorno-de-deficit-de-natureza.html>. Acesso em: 01 de ago. de 2018.

Por que o contato com a natureza é importante para as crianças. Blog do Planeta. 31 de out. de 2016(b). [Internet]. Disponível em: <http://epoca.globo.com/colunas-eblogs/blog-do-planeta/noticia/2016/10/por-que-o-contato-com-natureza-e-importante-paracriancas.html>. Acesso em: 01 de ago. de 2018.

ELIAS, Norbert. EI Proceso de la Civilización: investigaciones sociogenéticas y psicogenéticas. México: Fondo de Cultura Económica, 1989.

FIOCRUZ. Tuberculose. Agência Fiocruz de Notícias. 04 de jul. de 2013. [Internet]. Disponível em: 〈https://agencia.fiocruz.br/tuberculose> Acesso em: 01 de ago. de 2018.

FOUCAULT, Michel. Politique et éthique: une interview. In: Dits et Ecrits: 19541988. v.IV (1980-1988). Paris: Galimard, 1994, pp.584-590. 
Vozes, 1999.

Vigiar e Punir: nascimento da prisão. RAMALHETE, R. (Trad.). 20ed. Petrópolis:

O Nascimento da Clínica. Machado, R. (Trad.). Rio de Janeiro: Forense

Universitária, 2014.

JUNQUEIRA, Heloisa; KINDEL, Eunice Aita Isaia. Leitura e Escrita no Ensino de Ciências e Biologia: a visão antropocêntrica. Cadernos do Aplicação. Porto Alegre: UFRGS, vol.22, n.1, 2009, pp.145-161. Disponível em: 〈http://hdl.handle.net/10183/25484>. Acesso em: 19 de ago. de 2018.

LATOUR, Bruno. A Esperança de Pandora: ensaios sobre a realidade dos estudos científicos. Bauru: EDUSC, 2001.

LATOUR, Bruno; WOOLGAR, Steve. A Vida de Laboratório: a produção dos fatos científicos. Rio de Janeiro: Relume Dumará, 1997, 310p.

LOUV, Richard. A Última Criança na Natureza: resgatando nossas crianças do transtorno do déficit de natureza. AZUMA, A.; BELHASSOF, C. (Trad.). 1 ed. São Paulo: Aquariana, 2016, 412p.

Richard Louv - books. Last Child in the Woods. 2016. [Internet]. Disponível em: <http://richardlouv.com/books/last-child/>. Acesso em: 18 de ago. de 2018.

MARTINS, Thaís Presa. As Naturezas de Natura Ekos: vídeos publicitários constituindo consumidores “sustentáveis". Dissertação (Mestrado) - Programa de Pós-Graduação em Educação em Ciências: Química da Vida e Saúde, Universidade Federal do Rio Grande do Sul, Porto Alegre, 2016. Disponível em: 〈http://hdl.handle.net/10183/143381〉. Acesso em: 18 de ago. de 2018.

SCLIAR, Moacyr. História do Conceito de Saúde. PHYSIS: Rev. Saúde Coletiva. Rio de Janeiro, n.17, v.1, 2007, pp.29-41.

SOUZA, Nádia Geisa Silveira de. Que Corpo é esse? O corpo na família, mídia, escola, saúde... Tese [Doutorado em Bioquímica]. Porto Alegre, RS: Instituto de Ciências Básicas da Saúde/UFRGS, 2001.

VEIGA-NETO, Alfredo. A Ordem das Disciplinas. Tese [Doutorado em Educação]. Porto Alegre, RS: Faculdade de Educação/UFRGS, 1996.

WORTMANN, Maria Lúcia Castagna, et al. Apresentação. In: WORTMANN, M. L. C., et al. (Orgs.). Ensaios em Estudos Culturais, Educação e Ciência - A Produção Cultural do Corpo, da Natureza, da Ciência e da Tecnologia: instâncias e práticas contemporâneas. Porto Alegre: Ed. da Universidade/UFRGS, 2007, pp.7-18. 